\title{
IMPLEMENTASI METODE TADABBUR AL-QUR'AN DI PESANTREN AR-RAHMAN BOGOR
}

\author{
Syamsuar Hamka ${ }^{1}$ \\ Program Studi Pendidikan Agama Islam FITK IAIN Ambon ${ }^{1}$ \\ elfaatihabufath@gmail.com
}

\begin{abstract}
This research is a case study of qualitative research that aims to describe the Implementation of Tadabbur Method in Qur'anic Learning at Pesantren Ar-Rahman, Megamendung, Bogor. The scopes of this research are 1) The Concept of Tadabbur Method in Qur'anic Learning. 2). Implementation of Tadabbur Method in Qur'anic Learning at Pesantren ar-Rahman. Data collection is carried out by participatory observations and interviews with the director, teachers and students. The results of observations are processed through selection, classification, and direction so as could be concluded. Afterwards the data would be presented and analyzed to get the description of the Concept and Implementation of the Tadabbur Method in Qur'anic learning. From this research, it was obtained the description that the Implementation of Tadabbur Method in Qur'anic learning at Pesantren ar-Rahman is held on the weekly learning (Ta'lim Rutin Pekanan), where the implementation begins with preparation of tools and learning materials by 'mudarris', then continued with tadabbur motivation lifted from a couple of Qur'anic verses. Afterwards, reading the objective verse, write it down and mudarris would be explaining a brief interpretation and the meaning of its certain vocabulary. Then continued with appreciation (penghayatan), go deep into (pendalaman) the verses by optimizing the mind and heart, subsequently writing the wisdom that was obtained.
\end{abstract}

Keywords: Tadabbur Method, Qur'anic Learning, Pesantren

\begin{abstract}
Abstrak: Penelitian ini adalah penelitian kualitatif berjenis studi kasus (case study) yang bertujuan untuk untuk mendeskripsikan Implementasi Metode Tadabbur dalam Pembelajaran al-Qur'an di Pesantren Ar-Rahman, Megamendung, Bogor. Ruang lingkup penelitian ini adalah 1) Konsep Metode Tadabbur dalam Pembelajaran al-Qur'an. 2). Pelaksanaan Metode Tadabbur dalam Pembelajaran Al-Quran di Pesantren ar-Rahman. Pengambilan data dilakukan dengan observasi partisipatori dan wawancara bersama mudir, pengajar dan santri. Hasil observasi diproses melalui pemilihan data, penggolongan, dan pengarahan hingga kesimpulan finalnya dapat ditarik kesimpulan verifikasi. Kemudian disajikan dan dianalisis sehingga dapat memunculkan deskripsi tentang Konsep dan Implementasi Metode Tadabbur dalam pembelajaran al-Qur'an. Setelah itu dilakukan Penarikan Kesimpulan (verifikasi). Dari penelitian, diperoleh deskripsi bahwa Implementasi Metode Tadabbur dalam Pembelajaran al-Qur'an di Pesantren ar-Rahman dilangsungkan dalam ta'lim rutin pekanan, di mana pelaksanaannya dimulai dengan penyiapan alat dan bahan belajar oleh mudarris, kemudian dilanjutkan dengan motivasi tadabbur yang diangkat dari ayat-ayat al-Qur'an. Kemudian membaca ayat yang akan ditadabburi, menuliskan dan menjelaskan tafsir ringkas serta makna kosakata tertentu. Kemudian dilanjutkan dengan penghayatan, pendalaman dengan mengoptimalkan pikiran dan hati, setelah itu dituliskan hikmah yang diperoleh.
\end{abstract}

Kata kunci: Metode Tadabbur, Pembelajaran al-Qur'an, Pesantren 


\section{PENDAHULUAN}

Indonesia merupakan negara dengan penduduk muslim terbesar di dunia. Data yang diturunkan oleh forum.detik.com menunjukkan jumlah penduduk muslim Indonesia sebanyak 182.570 .000 orang, diatas Pakistan yang berjumlah 134.480.000 orang dan India, 121.000.000 orang (Detik, 21 Juni 2014).

Meskipun $88 \%$ penduduknya beragama Islam, tidak semua bisa membaca al-Qur'an. Berdasarkan hasil survei yang dilakukan Institut IImu al-Qur'an Jakarta pada 2012, 65 \% Umat Islam buta aksara al-Qur'an. Artinya, hanya 35 \% hanya yang bisa membaca al-Qur'an. Sedangkan yang bisa membaca dengan baik dan benar hanya 20 persen (jpnn, 6 Juni 2014).

Dari data di atas, perhatian umat Islam terhadap al-Qur'an sangat memprihatinkan. Oleh karena itu, harus dilakukan upaya yang lebih jelas dan nyata dalam meningkatkan mutu pendidikan al-Qur'an di tanah air. Hal itu didasarkan pada hadis Rasulullah SAW, "Didiklah anak-anakmu dengan tiga perkara, mencintai Nabimu, mencintai keluarga Nabi, dan membaca al-Qur'an“ (HR. Thabrani). Oleh karena itu, pendidikan alQur'an merupakan hal utama dalam mempersiapkan generasi.

Pendidikan merupakan usaha sadar untuk menumbuhkembangkan potensi Sumber Daya Manusia (SDM) melalui kegiatan pengajaran. Ada dua istilah dalam dunia pendidikan yang saling berkaitan, yaitu konsep belajar (learning) dan pembelajaran (instruction). Konsep belajar bersumber pada perspektif peserta didik sementera konsep pembelajaran bersumber pada perspektif pendidiknya (Sudjana, 1984).

Mengajar merupakan istilah kunci yang hampir tak pernah luput dari pembahasan mengenai pendidikan karena keeratan hubungan antara keduanya. Metodologi mengajar dalam dunia pendidikan perlu dimiliki oleh pendidik, karena keberhasilan Proses Belajar Mengajar (PBM) bergantung pada cara mengajar guru dan bagaimana membelajarkan peserta didiknya. Jika cara mengajar gurunya nyaman dan mudah dimengerti 
menurut peserta didik, maka mereka akan tekun, rajin, serta antusias menerima pelajaran yang diberikan. Hasilnya diharapkan akan terjadi perubahan pada pola pikir dan perilaku pada peserta didik yang ditandai dengan baik tutur katanya serta memiliki sopan santun dan keluhuran budi pekerti.

Tujuan pembelajaran yang diinginkan tentu yang optimal, untuk itu ada beberapa hal yang perlu diperhatikan oleh pendidik, salah satu diantaranya adalah metodologi pengajaran. Metodologi pengajaran banyak ragamnya, karena itu sebagai pendidik tentu harus menguasai berbagai jenis metode mengajar, agar dalam proses belajar mengajar tidak monoton. Penerapan metode yang tepat disesuaikan dengan tipe belajar siswa, kondisi serta situasi yang ada pada saat itu, sehingga tujuan pengajaran yang telah dirumuskan sendiri oleh pendidik dapat tercapai dengan baik.

Metode pengajaran yang perlu dibuat lebih bermakna adalah ketika mengajarkan al-Qur'an. Sebab berlama - lama dalam berinteraksi dengan al-Qur'an dengan hanya satu jenis metode pengajaran akan membuat peserta didik cepat jenuh dan bosan. Padahal dalam doktrin utama, untuk memahami ajaran Islam secara sempurna (kaffah), diperlukan pemahaman terhadap kandungan al-Qur'an dan mengamalkannya dalam kehidupan sehari-hari secara sungguh-sungguh dan konsisten.

Menurut Ibnu Khaldun dalam al-Muqaddimah, pendidikan al-Qur'an menjadi fondasi seluruh kurikulum pendidikan di dunia Islam, karena alQur'an merupakan syiar agama yang mampu menguatkan akidah dan mengokohkan keimanan (Khaldun, 2000). Ibnu Sina juga memberikan nasihat agar memperhatikan pendidikan al-Qur'an kepada anak-anak. Menurutnya segenap potensi anak, baik jasmani maupun akalnya, hendaknya dicurahkan untuk menerima pendidikan utama ini, agar anak mendapatkan bahasa aslinya dan agar akidah bisa mengalir dan tertanam pada kalbunya (Syarifuddin, 2007: 12). Dengan pendidikan al-Qur'an sejak dini, fitrah suci anak niscaya dapat dilestarikan dengan baik. 
Hal itu juga sejalan dengan kebijakan Pemerintah Indonesia. Terlihat dari Keputusan Bersama Menteri Dalam Negeri dan Menteri Agama RI nomor 128 tahun 1982/4A, yang menyatakan "perlunya usaha peningkatan kemampuan baca tulis al-Qur'an bagi umat Islam dalam rangka peningkatan penghayatan dan pengamalan al-Qur'an dalam kehidupan sehari-hari". Keputusan ini pula ditegaskan oleh Menteri Agama RI nomor 3 tahun 1990 tentang pelaksanaan upaya peningkatan kemampuan baca tulis huruf al-Qur'an (Syarifuddin, 2007).

Bagi umat Islam, salah satu cara untuk mewujudkan tujuan pembangunan tersebut adalah dengan meningkatkan pemahaman umat terhadap al-Qur'an dan hadist yang merupakan sumber ajaran Islam. Di mana untuk mendapatkan pemahaman mengenai al-Qur'an tidak cukup hanya dengan mengandalkan terjemah dan tafsirnya saja, namun diperlukan perangkat ilmu-ilmu lain atau kegiatan-kegiatan lain yang mendukung pemahaman tersebut. Beberapa cara untuk memperoleh pemahaman tersebut bisa dengan (Kemenag RI, 2011):

1. Mentadabburi ayat-ayat al-Qur'an dengan perhatian yang seksama

2. Mengulang hafalan

3. Khusyu saat membaca al-Qur'an

4. Tidak mengacuhkan al-Qur'an

Salah satu institusi yang menjadi pusat pendidikan al-Qur'an adalah pesantren. Di dalamnya diajarkan cara membaca, menghafal dan mengkaji kandungan al-Qur'an. Pada gilirannya, pondok pesantren menjadi pusat Tafaqquh fi al-Din (pendalaman pengetahuan agama) dan institusi Tarbiyah al-Akhlaq (pembentukan budi pekerti) yang didasarkan pada al-Qur'an.

Berdasarkan metodenya, Budi Ashari menyebutkan ada empat metode pembelajaran al-Qur'an, yaitu: Tartil, berkaitan dengan cara membaca sesuai kaidah tajwid.Tahfiz, berkaitan dengan menghafal alQur'an. Tafsir, berkaitan dengan penjelasan (ilmu baku) yang dibahas oleh 
pakarnya. Dan Tadabbur, berkaitan dengan perenungan tentang maknamakna al-Qur'an (Ashari, 2012).

Berdasarkan empat metode di atas, penulis mendapatkan porsi pembelajaran al-Qur'an di pesantren kurang seimbang. Dimana, pesantren sebagai institusi yang menjadi pusat pendidikan al-Qur'an, cenderung memiliki metode yang tidak variatif. Dalam pembelajaran alQur'an, hanya ditekankan pada tartil, tahfiz, dan tafsir semata. Sementara di sisi yang lain, cenderung mengabaikan penggalian makna dan pesanpesan ayatnya (tadabbur).

Padahal, mempelajari al-Qur'an sebatas tartil dan tahfiz tanpa disertai penggalian makna akan membuat suasana pembelajaran menjadi kurang efektif. Selain itu fungsi utama al-Qur'an sebagai al-huda (petunjuk) tidak terimplementasi secara maksimal. Karena pembelajaran tersebut hanya berorientasi pada teks. Padahal al-Qur'an seharusnya bisa membentuk karakter bukan sekedar tsaqofah keilmuwan. Hal tersebut bisa berimplikasi pada banyaknya santri yang menghafal al-Qur'an tapi tidak terbina dengan akhlak al-Qur'an. Salah satu penyebabnya adalah hampir belum ada pesantren yang mengimplementasikan metode tadabbur dalam sistem pembelajaran al-Qur'annya.

Oleh karena itu sebagai pesantren yang fokus pada pendidikan dan pembelajaran al-Qur'an, Ma'had Ar-Rahman lil-Qur'an atau yang lebih dikenal dengan Pesantren Ar-Rahman Bogor, mengembangkan satu jenis metode pembelajaran al-Qur'an berbasis tadabbur. Dengan metode tersebut diharapkan dapat membantu para santri memahami pesan-pesan al-Qur'an. Agar mereka mengerti apa isi atau kandungan al-Qur'an, serta apa amanah al-Qur'an bagi para penghafalnya (adab al-hamalat alQur'an).

Dengan metode tadabbur, diharapkan santri memiliki kepribadian yang diinginkan al-Qur'an atas mereka. Selain itu mereka lebih intensif dalam menggali dan memahami makna-makna al-Qur'an. Dalam jangka 
panjang mereka bisa melaksanakan al-Qur'an secara fungsional, bukan secara ritual semata.

Berdasarkan hal tersebut, sangat penting dilakukan penelitian lebih dalam tentang implementasi metode tadabbur di pesantren ini. Karena pembelajaran al-Qur'an dengan metode tadabbur masih sangat jarang dibahas dalam pembelajaran di pesantren. Sehingga tujuan jangka panjangnya, pembelajaran al-Qur'an dengan metode tadabbur bisa diterapkan di lembaga pendidikan Islam yang lain, baik formal, maupun non-formal.

\section{METODE}

Dalam penelitian ini, penulis menggunakan jenis penelitian studi kasus. Fokusnya adalah spesifikasi kasus dalam suatu kejadian baik yang mencakup individu, kelompok budaya ataupun suatu potret kehidupan dengan metode kualitatif. Subjek penelitian ini adalah mudir pesantren, Asatidz, dan Santri.

Pengumpulan data dilakukan dengan Observasi, wawancara, dan dokumentasi. Data yang telah diperoleh kemudian dianalisis dengan teknik analisis deskriptif meliputi tiga alur kegiatan, yaitu reduksi data, penyajian data, dan pemeriksaan kesimpulan atau verifikasi (Surakhmad, 1990).

\section{HASIL}

\section{Konsep Metode Tadabbur}

Tadabbur berasal dari kata tadabbara - yatadabbaru, yang berarti (1) mencerminkan, mempertimbangkan, merenungkan. (2). Engatur, mengurus, memelihara. (3) mendapatkan (Kamus al-Ma'any). Pakar tadabbur al-Qur'an, Bachtiar Nasir menyebutkan bahwa Tadabbur adalah memandang sesuatu di balik sesuatu dan memahami akibat yang ditimbulkannya (Nasir, tt). 
Secara umum tadabbur bisa diartikan dengan upaya merenungkan, menghayati dan memikirkan, dan mengkombinasikan penggunaan akal dan hati mencari pesan-pesan di balik ayat-ayat al-Qur'an.

Pembelajaran al-Qur'an dengan metode Tadabbur adalah pembelajaran al-Qur'an yang bertujuan untuk membuka qolbu agar dapat merasakan keagungan ayat-ayat al-Qur'an dan untuk membuktikan bahwa al-Qur'an sungguh-sungguh berasal dari Allah untuk kemudian mentaati kandungannya. Hal tersebut berawal dari pendalaman terhadap al-Qur'an. Allah SWT menyebutkan,

"Kitab (al-Qur'an) yang Kami turunkan kepadamu penuh berkah agar mereka mentadabburi (menghayati) ayat-ayatnya dan agar orang-orang yang berakal sehat mendapat pelajaran"(QS. Shad: 29) menyebutkan,

Dalam menafsirkan ayat di atas, Imam at-Thabari

Liyaddabaru Ayatihi, maksudnya adalah agar mereka merenungkan argumen-argumen Allah di dalamnya, dan berbagai syariat yang ditetapkan-Nya di dalamnya, sehingga mereka memetik nasihat dan mengamalkannya. Wal Yatadzakkaru Ulul Albaab adalah, agar orang yang memiliki akal dan pikiran memetik pelajaran dari ayatayat yang terdapat di dalam kitab ini (al-Qur'an), sehingga mereka terhalau dari kesesatan dan mereka berpegang teguh serta mengikuti petunjuk dan jalan kebenaran yang ditunjukkan kepada mereka (At-Thabari, 2009, XXII : 147- 148)

Sejalan dengan hal di atas, Muhammad Said Ramadhan Buthi menyebutkan dalam Minhaj Tarbawi Faried fil Qur'an dikutip Hamdani Ihsan (Ihsan dan A. Fuad Ihsan, 2007), ada tiga macam asas atau dasar yang dipakai untuk menanamkan pendidikan yaitu,

1. Muhkamah Aqlyah, mengetuk akal pikiran untuk memecahkan segala sesuatu. Di dalam tingkat ini, al-Qur'an menyadarkan setiap akal manusia untuk memikirkan asal-usul dirinya, mulai dari asal mula kejadiannya, kemudian perkembangannya, baik fisik maupun akal dan ilmunya atau mental spiritualnya. Sesudah itu dibawanya kepada alam cakrawala yang luas terbentang ini, yang semuanya menggunakan kata-kata yang dapat diikuti oleh orang-orang awam 
dan dapat dijadikan bahan penyelidikan secara ilmiah oleh para sarjana.

2. Al Qishah wa at-Tarikh, menggunakan cerita-cerita dan pengetahuan sejarah. Dengan menggunakan berbagai cerita atau peristiwa, dan dengan membuka lembaran-lembaran sejarah di masa dahulu untuk melihat dirinya. Berbagai cerita yang disebut oleh al-Qur'an menghidupkan sejarah-sejarah bertujuan untuk memberanikan hati manusia dalam zaman yang dihadapinya dan mengisi masa depan dengan pendidikan kepada anak-anak.

3. Al Itsrah al Wijdaniyah, memberikan perangsang kepada perasaanperasaan. Membangkitkan rangsangan perasaan, adalah jalan yang terpendek untuk menanamkan suatu karakter kepada anak-anak. Dan perasaan-perasaan itu terbagi dalam,

a. Perasaan pendorong, yaitu rasa gembira, harapan, hasrat yang besar dan sejenisnya

b. Perasaan Penahan, yaitu rasa takut (berbuat kejahatan), rasa sedih (berbuat kezaliman), dan sejenisnya.

c. Perasaan Kekaguman, yaitu rasa hormat dan kagum, rasa cinta, rasa bakti, dan pengabdian, dan sejenisnya.

Memberikan perangsang terhadap perasaan-perasaan ini menurut tempat dan waktu yang tepat, menimbulkan kesan yang mendalam kepada anak didik.

Dalam metode tadabbur, para santri diarahkan untuk lebih berta'ammul (memusatkan perhatian) terhadap al-Qur'an. Selain itu, santri diarahkan untuk menulis dan menemukan sendiri pesan-pesan tersirat di balik ayat-ayatnya. Dengan demikian, pengaruh al-Qur'an akan lebih terasa, karena al-Qur'an memerintahkan untuk merenungkan (yatadabbar) dan mengambil pelajaran (yatadzakkar). Tidak terbatas pada cara membaca, menghafal atau sekedar mengerti hukum-hukum yang terkandung di dalamnya. Karena al-Qur'an diturunkan untuk digali dan dipahami pesan-pesan ayatnya. 


\section{Implementasi Metode Tadabbur al-Qur'an di Pesantren ar-Rahman Bogor}

Dari observasi, wawancara dan dokumentasi peneliti, diperoleh hasil pengamatan implementasi metode tadabbur di Pesantren ar-Rahman Bogor melalui beberapa tahap. Dimana sebelum memulai pengajaran tadabbur terlebih dahulu dilakukan persiapan. Dalam hal ini menyiapkan sarana dan prasarana yang menunjang selama pengajaran berlangsung seperti meja dan kursi yang digunakan oleh mudarris pada saat menyampaikan materi, laptop mudarris, proyektor, sound system, juga mushaf yang disertai terjemahan yang memiliki standar Kemenag Rl, dan buku tulis yang disiapkan oleh masing-masing santri untuk digunakan selama pembelajaran berlangsung. Pada saat menyampaikan materi tadabbur al-Quran mudarris akan duduk di kursi yang telah disediakan di depan majelis. Mudarris menghadap ke santri, dan santri duduk di lantai masjid berbaris tertib menghadap mudarris.

Dalam melakukan pembelajaran tadabbur al-Qur'an tahapan yang dilalui adalah sebagai berikut :

Tabel 1. Tahapan Kegiatan dan Implementasi Pembelajaran Tadabbur alQur'an di Pesantren ar-Rahman, Bogor.

\begin{tabular}{|c|c|c|}
\hline $\begin{array}{l}\text { Tahapan } \\
\text { Kegiatan }\end{array}$ & Kegiatan Mudarris & Kegiatan Santri \\
\hline $\begin{array}{l}\text { Kegiatan } \\
\text { Pembuka } \\
\text { (Apersepsi } \\
\text { dan } \\
\text { Motivasi) }\end{array}$ & $\begin{array}{l}\text { Mengucapkan salam, } \\
\text { dilanjutkan dengan syukur dan } \\
\text { shalawat serta doa dalam } \\
\text { bahasa arab } \\
\text { - } \\
\text { Menjelaskan secara singkat } \\
\text { tentang definisi tadabbur } \\
\text { secara bahasa, hakikat } \\
\text { tadabbur dan urgensi tadabbur } \\
\text { al-Quran } \\
\text { - Mengutip ayat QS Shad ayat } 29\end{array}$ & $\begin{array}{l}\text { - } \quad \text { Menjawab salam } \\
\text { - Diam } \\
\text { mendengarkan } \\
\text { penjelasan }\end{array}$ \\
\hline $\begin{array}{l}\text { Kegiatan } \\
\text { Inti }\end{array}$ & $\begin{array}{ll}\text { - } & \text { Menyampaikan ayat yang } \\
& \text { ditadabburi } \\
\text { - } & \text { Membacakan QS al-Falaq ayat } \\
& 1-5 \\
\text { - } & \text { Mengulanginya sebanyak tiga }\end{array}$ & \\
\hline
\end{tabular}




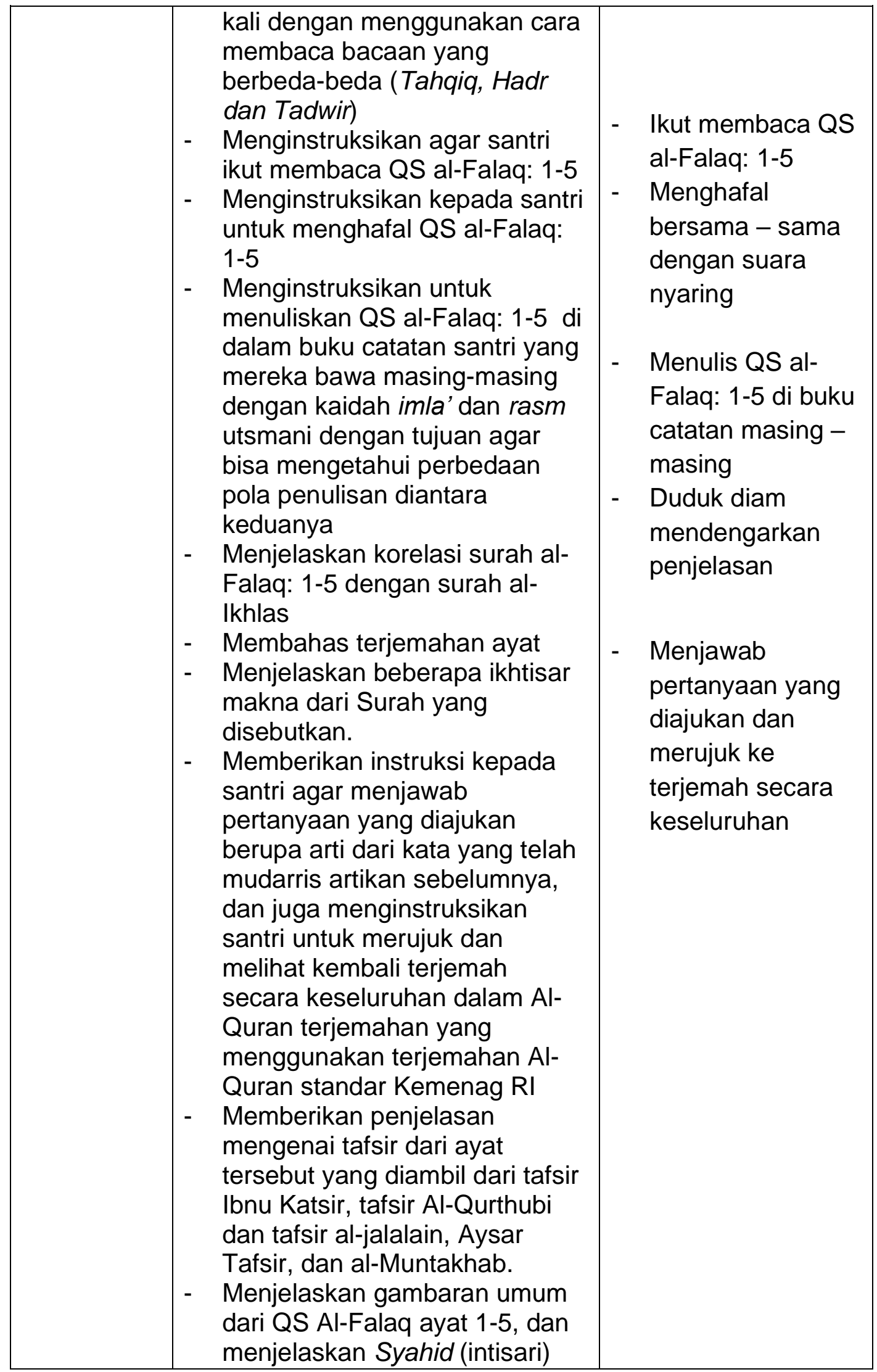




\begin{tabular}{|c|c|c|}
\hline & $\begin{array}{l}\text { dari hasil tadabbur nya. } \\
\text { - } \quad \text { Menjelaskan pesan-pesan } \\
\text { utama dari ayat sesuai } \\
\text { wawasan keilmuan mudarris. } \\
\text { - } \quad \text { Mengarahkan dengan memberi } \\
\text { instruksi santri untuk } \\
\text { menghubungkan ayat tersebut } \\
\text { dengan kehidupan sehari - } \\
\text { hari. } \\
\text { Menjelaskan, dan } \\
\text { menginstruksi para santri untuk } \\
\text { menghayati bahwa surat } \\
\text { tersebut adalah tanda bahwa } \\
\text { Allah Maha Menyayangi } \\
\text { manusia, dan agar manusia } \\
\text { menyandarkan keselamatan } \\
\text { hanya kepada Allah. }\end{array}$ & $\begin{array}{l}\text { - Santri berpikir dan } \\
\text { menyebutkan } \\
\text { fenomena yang } \\
\text { berkaitan dengan } \\
\text { kehidupan sehari - } \\
\text { hari }\end{array}$ \\
\hline $\begin{array}{l}\text { Kegiatan } \\
\text { Penutup }\end{array}$ & $\begin{array}{l}\text { - Memberi kesempatan untuk } \\
\text { bertanya kepada santri dan } \\
\text { membuka diskusi terkait materi } \\
\text { yang telah dipelajari. } \\
\text { - Menutup pembelajaran dengan } \\
\text { doa kafaratul majlis, dan salam. }\end{array}$ & 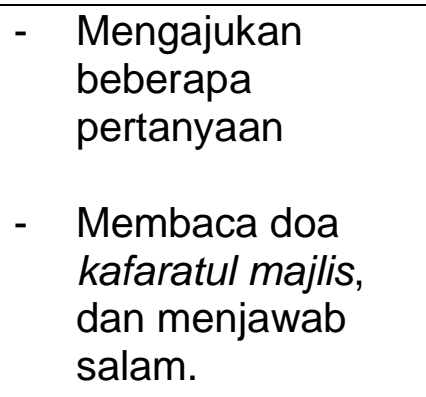 \\
\hline
\end{tabular}

Tabel di atas menunjukkan langkah-langkah implementasi metode tadabbur. Dimana terlihat ada interaksi aktif antara mudarris dan santri. Mudarris mengarahkan dan memberi instruksi, kemudian santri mengikuti instruksi dan menerima penjelasan dari mudarris.

\section{PEMBAHASAN}

Dari hasil observasi di atas diperoleh bahwa dalam implementasi metode tadabbur, santri ditekankan untuk menghayati dan melibatkan perasaan saat tahap pembacaan ayat al-Qur'an. Hal tersebut terlihat dimana mereka sangat fokus, ketika sedang membaca al-Qur'an dengan suara yang nyaring.

Jika ditelaah melalui teori pembelajaran yang ada, teori yang paling bisa menjelaskan Metode Tadabbur ini adalah teori belajar bermakna, 
David Ausubel. Dimana menurutnya, pembelajaran bermakna terjadi apabila seseorang belajar dengan mengasosiasikan fenomena baru ke dalam struktur pengetahuan mereka. Dalam proses belajar tersebut, seseorang mengkonstruksi apa yang telah ia pelajari dan mengasosiasikannya dengan apa yang pernah mereka alami, fenomena apa yang mereka pernah lihat, dan juga fakta-fakta baru untuk masuk ke dalam struktur kognitif mereka (Rahmah, 2013). Jadi dalam metode tadabbur ini para santri mengkonstruksi makna-makna yang mereka peroleh lewat teks al-Qur'an, serta mengaitkannya dengan pengetahuan dan pemahaman mereka sebelumnya. Baik pengetahuan tentang kebahasaaan, tafsir, asbab an-nuzul, serta ayat dan hadits lain yang mereka ketahui.

Padahal menurut David Ausubel, kunci keberhasilan belajar terletak pada kebermaknaan bahan ajar yang diterima atau yang dipelajari oleh siswa. Jika informasi atau pengalaman baru bermakna bagi siswa, maka siswa dapat memahaminya dengan mudah dan sedikit kemungkinan mengalami kesulitan dalam menyusun suatu kesimpulan yang merupakan hasil interaksi antara pengetahun baru dan pengetahuan yang dimiliki sebelumnya. Jadi kebermaknaan suatu bahan ajar sangat ditentukan oleh keterkaitannya dengan pengetahuan yang dimiliki anak didik, bukan dari proses mendapatkan pengetahuan tersebut. Ausubel tidak setuju dengan pendapat bahwa kegiatan belajar penemuan lebih bermakna daripada kegiatan belajar. Dengan ceramah pun, asalkan informasinya bermakna bagi peserta didik, apalagi penyajiannya sistematis, akan memperoleh hasil belajar yang baik pula.

Sehingga, jika pembelajaran dilakukan dengan metode tadabbur, penanaman makna-makna ayat al-Qur'an akan lebih kuat dan lebih mampu memberikan kesan kepada para santri dalam pendidikan alQur'an.

Dengan demikian diperoleh bahwa inti dari tadabbur adalah perenungan ayat, dan pendalaman secara berulang-ulang, pengamatan 
secara rinci rangkaian ayat serta pengamatan secara rinci rangkaian ayat, susunannya, maknanya, proses turunnya, lafadz gharib-nya, dan mencermati konotasi ayat. Selain itu, makna-makna itu ditarik ke alam realitas dengan cara menjadikan ayat sebagai titik tolak bagi solusi kehidupan yang mereka hadapi, serta sebagai kriteria bagi lingkungannya.

Karena itu, dalam penelitian ini diperoleh bahwa metode tadabbur bisa lebih efektif jika para peserta didiknya sudah memiliki ilmu-ilmu dasar dalam bahasa dan tafsir. Sehingga kualitas tadabbur seseorang tergantung pada pengetahuan dan ilmu mereka dalam bertadabbur. Terdapat empat faktor pendukung tadabbur, yaitu : Pertama, Kejernihan hati, karena al-Qur'an adalah cahaya. Dan al-Qur'an hanya masuk dalam hati yang suci. Kedua, kemahiran terhadap al-Qur'an, mencakup kemampuan membaca dengan kaidah-kaidah tajwid. Ketiga, Kemampuan berbahasa arab. Keempat, Kemampuan merujuk kepada tafsir-tafsir yang ada.

Meskipun demikian, setiap orang dapat bertadabbur al-Qur'an. Karena tadabbur bisa dilakukan oleh siapa saja dengan bantuan terjemah atau kitab-kitab tafsir yang ada.

Tadabbur dalam pembelajaran al-Qur'an bisa dikatakan adalah kelanjutan dari fase tahsin dan tahfiz. Artinya, tadabbur seseorang akan lebih berkualitas jika dilandasai oleh tahsin atau bacaan al-Qur'an yang baik dan hafalan yang baik pula. Begitu pula, bisa dianggap metode tadabbur ini membantu dalam menghafal al-Qur'an. Karena dengan bertadabbur, proses menghafal akan lebih mudah karena dibantu dengan asosiasi cerita atau pun alur pembicaraan pada ayat yang dihafal.

Dengan demikian, tadabbur, tahsin, tahfiz dan tafsir adalah metode yang sama-sama saling melengkapi. Yang menjadi dasar dalam pembelajaran al-Qur'an adalah tahsin. Dilanjutkan tahfiz, kemudian tafsir dan tadabbur. Akan tetapi dalam fasenya, Tadabbur dapat memudahkan hafalan, begitu pula tafsir. Sehingga diketahui bahwa keempat metode ini, saling terkait satu dengan yang lain. 


\section{KESIMPULAN}

Berdasarkan pembahasan pada bagian sebelumnya, penulis menyimpulkan bahwa Implementasi Metode Tadabbur dalam Pembelajaran al-Qur'an di Pesantren ar-Rahman Bogor dilangsungkan sekali dalam sepekan, yaitu dalam ta'lim rutin pekanan, di mana pelaksanaannya dimulai dengan penyiapan alat dan bahan belajar oleh mudarris, kemudian dilanjutkan dengan motivasi tadabbur yang diangkat dari ayat-ayat al-Qur'an. Kemudian membaca ayat yang akan ditadabburi, menuliskan dan menjelaskan tafsir ringkas serta makna kosakata tertentu. Kemudian dilanjutkan dengan penghayatan, pendalaman dengan mengoptimalkan pikiran dan hati, setelah itu dituliskan hikmah yang diperoleh.

Tadabbur dalam pembelajaran al-Qur'an bisa dikatakan adalah kelanjutan dari fase tahsin dan tahfiz. Artinya, tadabbur seseorang akan lebih berkualitas jika dilandasai oleh tahsin atau bacaan al-Qur'an yang baik dan hafalan yang baik pula. Akan tetapi bisa juga dianggap metode dalam membantu menghafal al-Qur'an. Karena dengan tadabbur, bisa memudahkan seseorang untuk menghafal.

Dengan demikian, tadabbur, tahsin, tahfiz dan tafsir adalah metode yang sama-sama saling melengkapi. Metode yang paling dasar dalam pembelajaran al-Qur'an adalah tahsin, dilanjutkan tahfiz, kemudian tafsir dan tadabbur. Dalam perkembangannya, Tadabbur dapat memudahkan hafalan, begitu pula tafsir. Sehingga diketahui bahwa keempat metode ini, saling berkaitan dan menguatkan satu dengan yang lain.

\section{DAFTAR PUSTAKA}

[1] Abdul Qadir Ahmad, Muhammad, Metodologi Pengajaran Agama Islam. Jakarta: Rineka Cipta, 2008.

[2] Ashari, Budi, Al-Fatih; Pilar Peradaban. Depok: Yayasan Al-Fatih, 2012. 
[3] At-Thabari, Tafsir At-Thabari (Jilid XXII). Jakarta: Pustaka Azzam. 2009.

[4] http://forum.detik.com/10-negara-dengan-jumlah-penduduk-muslimterbesar-di-dunia-t252419.html.

[5] http://www.jpnn.com/read/2013/07/07/180493/65-Persen-MuslimButa-AI-Quran-

[6] Ihsan, Hamdani dan A. Fuad Ihsan, Filsafat Pendidikan Islam, Bandung: CV. Pustaka Setia. 2007.

[7] Khaldun, Ibnu, Al-Muqaddimah. Jakarta: Pustaka Firdaus. 2000.

[8] Lajnah Pentashihan mushaf alquran Badan Litbang. Keutamaan Alquran dalam kesaksian hadist, penjelasan seputar Keutamaan surah ayat dan ayat al-Quran. Jakarta: Kemenag RI. 2011.

[9] Nasir, Bachtiar, Tadabbur al-Qur'an. Jakarta: AQL-Pustaka, Tanpa Tahun

[10] Sudjana, Nana, Dasar-Dasar Belajar Mengajar. Bandung: Sinar Baru Algensindo.1984

[11] Surakhmad, Winarno, Pengantar Penelitian Ilmiah Dasar Metode Teknik. Bandung: Tarsito. 1990.

[12] Syarifuddin, Ahmad, Mendidik Anak, Menulis, dan Mencintai AlQuran. Jakarta: Gema Insani Press. 2007.

[13] Hamdani Ihsan dan A. Fuad Ihsan, Filsafat Pendidikan Islam, Bandung : CV. Pustaka Setia. 2007.

[14] Rahmah, "Belajar Bermakna Ausubel", Khwarizmi J. Pendidikan Matematika STAIN Palopo, Vol.I, Maret 2013, doi : 10.24256/jpmipa.v1i1.54 